\title{
Civic Ecology Education and Resilient Societies: a Survey of Forest Fires in Greece
}

\author{
Konstantina Papaspiliou, Constantina Skanavis \& Christos Giannoulis \\ University of the Aegean. Department of Environment, Research Unit of Environmental Communication and Education, \\ Mytilene, Greece \\ Correspondence: Constantina Skanavis, University of the Aegean. Department of Environment, Research Unit of \\ Environmental Communication and Education, University Hill, Mytilene, 81100, Greece.
}

Received: November 8, 2013 Accepted: November 20, 2013 Online Published: January 24, 2014

doi:10.11114/jets.v2i2.271

URL: http://dx.doi.org/10.11114/jets.v2i2.271

\begin{abstract}
Forest fires, as all natural disasters, have the potential to seriously affect both the environment and the social structure of a local community. Unlike some of the natural disasters, such as hurricanes, tornados and tsunamis which are unpredictable, the phenomenon of forest fires could be easily predicted and controlled, since the causes are mainly anthropogenic. This article, focusing on the paradigm of forest fires that occurred in Greece during the summer of 2007, deals in depth with the significant role that Civic Ecology Education plays in the promotion of resilient societies. Given the fact, that the specific forest fires resulted in an unusually high death toll, the article argues about the need for successful environmental education for resilience in order to avoid similar tragedies. Increasing the social tolerance to natural hazards and directing communities' efforts towards strengthening sustainable development in their area should become common practices everywhere.
\end{abstract}

Keywords: natural disasters, forest fires, civic ecology, Environmental Education, urban Environmental Education, volunteering, resilience, recovery, Greece, local community, active citizens, sustainable development.

\section{Overview}

\subsection{Natural disasters}

Natural disasters have the potential to affect our lives irreversibly. Assessing the occurrence and consequences of nature's anger, couple points attract researchers' interest. The majority of natural disasters seem to be the outcome of two major factors, which interact with each other. On the one hand, natural disasters come as the result of the human actions and on the other side they are connected with various ecosystem dynamics. A natural disaster is therefore, the result of an ongoing process that combines human interaction and nature's explosion, rather than a single phenomenon that occurs instantaneously and independently of other factors (Hoffman \& Oliver-Smith 2002).

The related data indicate, that the number of deaths and logistical losses caused by natural disasters, on a global scale, is steadily increasing (Abbott 2013). The consequences of natural disasters are divided, into those, which directly threaten the human life, and to the ones, which jeopardize the stable structures and the successful functioning of human societies. The latter is an indirect and long-term effect, based on economic impact experienced by the affected geographic region. It is not unusual, to have the migration of communities hit by a natural disaster, and then the consequences present pressure to other geographic regions as well. There are indications that bring the cost of the natural disasters to at least $\$ 50,000,000,000$ per year, of which two thirds are direct consequences caused by the disaster and the rest are related to mitigation due to them (Abbott 2013).

Indirect losses, related to business' operation, however, are those that dramatically increase the recovery period after a natural disaster. Since $1990,20 \%$ of the losses in business profits are due to nature's catastrophes. Within this context, it is obvious that communities and companies, which have not developed resilient mechanisms, would become hostages of a potential natural disaster. The economic weakening of the society, caused by natural disasters, leads to the deterioration of living standards and to the gradual increase of unemployment (Mutter 2010).It is evident, however, that in industrialized countries, natural disasters have little economic impact in the long scale while in developing countries the occurrence of natural disasters slows dramatically the economic development of these regions (Abbott 2013). During the period 1985-1999, the losses of wealthier countries, related to the natural disasters, amounted to $2 \%$, while 
in the less fortunate countries, it reached the13\% (Mutter 2010). Wildfires are categorized as a quite common natural disaster. Wildfires mostly, seem to be directly depended on the human factor, as they, unlike other natural disasters, such as for example earthquakes or windstorms, are among the most predictable and manageable by human societies.

\subsection{Forest Fires}

Each fire incident presents its own dynamics and behaviour. Depending on the level in which a fire is moving relative to the ground, forest fires are divided into three sub-categories: basement fires, creeping ground fires and crown fires (Coch 1996).

There are many reasons that could become the cause of a forest fire, varying in the different geographic locations and climate conditions. Their causes are classified into natural and anthropogenic. The natural causes of forest fires are the result of natural phenomena such as the drought and the lightning. The lightning and the thunders are perhaps, two of the earliest known causes of forest fires, where the native vegetation often is behind burning outcome. Nevertheless, nowadays, the lightning as a cause of forest fires represents less than $10 \%$ on a global scale (Smith 2001). In addition, high temperatures and dry seasons are the most dangerous conditions that contribute decisively to a forest fire. The highest risk areas are identified in Mediterranean countries, where the climate plays a decisive role (Smith 2001).

The gradual and steady expansion of human activities in areas dominated by natural vegetation has increased dramatically the occurrence of forest fires, resulting to significantly high losses of human life and economic infrastructure (Abbott 2013).Picnics, bonfires in camping, lit cigarettes thrown from cars or trains, broken bottles that serve as focal lenses, are just some of the well identified causes of fires, all connected to pure negligence (Coch 1995). In Mediterranean countries (France, Italy, Greece, Spain),the high temperatures that are developing during summer and the increased number of tourists which indicate an increased human activity in coastal areas could explain the expansion of the phenomenon of sudden forest fires during the period June-September.

Coastal pine forests are no exception to the rule. Main causes of intentional fires here are arsons, for land development (Coch 1995). This is very often in regions like Corsica and in some areas of Italy, Greece, Turkey and Algeria (Keely 2012). During the last decades, forest fires have escalated public interest in the Mediterranean region. Greeceis a vivid example of this.

\subsection{Forest Fires in Greece}

Woodland, grassland and shrub land in rural or suburban Greek areas continue to partially or completely get destroyed by fires with severe environmental, social and economic impacts (Bassi \& Kettunen 2008).

The survey analyzed in this article concerns the forest fires that took place in the Peloponnese and particularly in the region of Ilia in 2007, mainly because those forest fires cost,in contrast with other similar fire disasters, an unusually high death toll. The specific forest fires occurred in the region of Peloponnese during the summer of 2007, burned thousands of hectares of land and more specifically forests (56,928 ha), forest land (60,260 ha), grassland (17,777 ha), agricultural land (42,596 ha) and other land (12,391 ha) (Koutsias \& Arianoutsou 2012). Despite the significant environmental destruction, which was attributed to the 2007 forest fires in the Peloponnese, the major outcry was the loss of 67 lives. This fact led to the identification of forest fires in the region of Peloponnese, as the most extreme natural disaster that has occurred in the recent Greek environmental history (Koutsias \& Arianoutsou 2012).

While European policies and measures related to the prevention and suppression of forest fires have been proven effective, extreme climatic conditions have placed countries like Portugal and Greece in absolute danger due to catastrophic fires(Bassi \& Kettunen 2008) bringing up theories towards the construction of resilient societies.

\subsection{Need for Resilient Societies}

The term resilience has its origins back in 1970 and comes from the field of ecology. More precisely C. S. Holling described resilience as a measure of resistance that the systems develop and as their ability to absorb change and disturbance, maintaining stability in the relationships between populations or state variables (Holling 2002). In brief, resilience is better described as the ability of a system to absorb disturbances and to maintain its basic function and structure (WalkerandSalt 2006, Folkeetal. 2010). In addition, Carpenter (2011) supports the opinion that the idea of resilience could be better described via the determination of three main characteristics: (1) the level of disturbance that a system can absorb, remaining in the same situation or at least the same attractive (2) the level that a system is capable of self-organization (3) the ability to create and to increase learning and adaptation.

In the bibliography of ecology can be traced three distinguished and widely known forms of resilience (Folke 2006, Holling 2002). The first type of resilience called mechanical resilience concerns the stability of a system in the terms of the equilibrium or of the stable situation. In this framework, resilience is described in terms of elasticity and emphasis is given to the persistence to the disturbance, and to the restoration to the previous situation. The second type of resilience is called ecological resilience and refers to the disturbances and to the shocks that have as result the complete 
transformation of a system through the creation of brand new structures and behaviors (MacKinnon and Derickson 2012). The third type of resilience which is called socio-ecologic resilience concerns the ideas of governance and management and suits better in the case of environmental disasters discussed in this article.

To support this argument Folke (2006) underlines that the first type of resilience namely mechanical resilience, is considered to be too narrow to be used in the case of environmental disasters because it focuses on the efficiency of the function and on the maintenance of the systems' stability through the resistance at the disturbance. The second type of resilience namely ecological resilience is connected mostly to the concept of ecosystems, but it can not be applied in the case of the human societes although Adger (2005) tried to describe the social form of resilience borrowing the context and the data used in the case of ecological resilience. Within the context of sustainability and environmental management, the concept of resilience after the occurrence of a natural disaster is related to the ability of a socio-ecological system to absorb the existing disturbances, to organize itself and to maintain its fundamental structures and functions (Walker 2012). This is the case of the third type of resilience, the socio-ecologic resilience which is related to the ways that the socio-ecological systems incorporate the ideas of adaptation, learning and self-organization with their ability to absorb disturbance (Folke 2006).

Extreme events, such as the massive environmental disasters-whether they are natural or technological-have long-term effects in social and ecological level, hindering recovery efforts of communities who have been injured by them. Every major environmental disaster that recently hit the planet, as Hurricane Katrina in the U.S., and the massive forest fires of 2009 in Australia and of 2012 in America, caused extensive losses within the injured areas both in environmental and social levels. Considering the environmental and the social impact of these disasters requires the reassessment of practices and policies for managing environmental disasters more effectively. Those practices and policies, applied by the social and ecological systems, during and the day after a major environmental catastrophe, are directly associated with recovery, which is so important (Petseti, 2009).

Within this context, it is clear that reducing the risk of a natural disaster and managing the issues of recovery and growth that follow the catastrophe are modern world's immediate concerns. For example, inequalities related to income of certain social groups and the lack of adequate infrastructure in both local and national level have contributed to increasing losses, human and material in case of forest fires in suburban areas. In this sense, the recovery of a local society from a natural disaster and reducing the vulnerability of specific groups living within it, it is not only a matter of the reconstruction of buildings and other related logistics infrastructure. It is related to the resilient mechanisms that make community residents more resistant to risk and less vulnerable to the adverse consequences resulting there from the potential hazardous situation (Lyons 2013, Khan 2005).

In an effort to regain the elasticity of the social fabric, in order to address the effects of a natural disaster and subsequent recovery in a society, certain factors can become a real asset. The awareness, improved educational programs, effective cooperation between institutions, mobilization of expertise and governance at multiple scales are some of the elements that reduce the vulnerability of a society and build resilience and tolerance in case of such risks (Tompkins 2012, Carpenter 2012). The failure of reduction phenomena, that contribute to social vulnerability caused by a natural disaster, can bring risks much greater than the natural disaster itself (Carpenter 2012).

Having structures that increase preparedness and tolerance of a society to natural disasters, requires effective governance systems and infrastructure, which should be covered by an adequate capacity to adapt to the risk of an environmental disaster (Rogerson 2005).

\subsection{Need for Civic Ecology Education}

The Declaration of Tbilisi, which has become the basic theoretical framework for Environmental Education, emphasized that the ultimate goal of Environmental Education is to promote human behavior and orientation, to a new environmentally responsible one. Within this framework, Environmental Education has been defined as "a process aimed at developing a world population that is aware of and concerned about the total environment and its associated problems, and has the attitudes, motivations, knowledge, commitment and skills to work individually and collectively towards solutions of current problems and the prevention of new ones" (Tsiblisi Declaration, as summarized in Stapp, 2001).

Environmental education, encompassing diverse and sometimes contradictory pedagogical approaches (Krasny \& Tidball 2010) involves the formation of different experiences on activities for nature conservation, as well as creating educational technologies and methods designed to mold a responsible human behavior toward the environment (Vaselinovska \& Gokik 2011). Fundamental variables, through which Environmental Education is promoted effectively, are the family, the school and the wider social environment, the media and non-governmental organizations (Keith 2001). Environmental education to the extent that equips citizens with experience handling complex problems, arising directly from the daily contact with its surroundings, is considered one of the main components of a modern system design, where the participation of all interested parties is mandatory (Skanavis 2005). 
The recent expansion of environmental education to encoppass Education for Sustainable Development, which seeks to "encourage changes in behavior that will create a more sustainable future in terms of environmental integrity, economic viability, and a just society for present and future generations (UNESCO 2002), further suggests a need for educational approaches that take place within the context of communities, including in cities, so as to better foster learning about social as well as ecological processes (Tidball \& Kransy 2010). Within the same context, calls for a place-based education that is rooted in local bio-physical as well as social place (Ardoin 2006) reinforce the need to further explore models of linked community-environmental experiences for the population living in large communities and cities. As proposed in the international bibliography those models could combine the methods of the traditional environmental education with the environmental education practices namely urban environmental education and civic ecology education in order to meet the expectations of the modern communities and cities as well.

Frank et al. (1994) describe urban environmental education as having "the same objectives as traditional environmental education: to encourage awareness, knowledge, attitude formation, skill development, and participation in solving environmental problems," while also being "unique because it happens in urban areas, with urban people, and deals with urban environmental systems and issues." These authors suggest three approaches in urban environmental education: studies of the natural environment (e.g., inventories of city birds, trees and insects); studies of the built environment (e.g., understanding issues related to waste and water treatment in cities); and service learning and action projects (including making direct improvements such as planting community gardens, investigating environmental issues, and community action such as distributing flyers on water conservation). Other approaches to urban environmental education have similarly adapted traditional approaches to an urban setting.

In adittion to urban environmental education, the term civic ecology education is used in order to describe "urban environmental education programs that engage youth in community-based stewardship to restore vacant lots, brown fields, stream sides, and other degraded habitats" (Tidball and Krasny 2007; Krasny and Tidball 2009; 2010). Such programs integrate several long-standing environmental education approaches, including nature contact and democratic deliberation, while also reflecting the fact that the activities take place in urban areas, with urban people, and deal with urban environmental systems and issues (cf. Frank et al. 1994). In particular, civic ecology education considers urban areas as linked social-ecological systems, includes opportunities for young people to learn from the practical and diverse knowledge of urban stewards (e.g., community gardeners), and focuses on restoration of urban social-ecological systems (Kransy and Tidball 2010). Where possible, it incorporates other elements of environmental education, including science learning, reflection on stewardship practice, communication skills (Kudryavtsev et al. In Press), and engagement in decision-making and policy processes.

The underlying principle of civic ecology education is that rather than viewing humans as acting principally to destroy otherwise healthy systems, humans can be seen as nested within (Wimberley 2009) and able to take action to improve communities and ecosystems. More particularly, the term civic ecology reflects the linked social and ecological systems implications of participatory environmental restoration and management initiatives in cities and elsewhere. Though that civic ecology emerges from the actions of of local residents wanting to make a difference in the social and natural environment of their community and is recognizable when both people and the environment benefit measurably and memorably from these actions, its educational approaches, perspectives and goals meet the requirements of resilient societies towards a natural hazard which anytime could be evolved in a massive natural disaster such as the forest fires occurred in Greece during the summer of 2007.

Although various approaches to civic ecology education are possible, situating educational practices in community-based activities allows programs to connect with growing movements focusing on urban ecological citizenship (Light 2003) and civic renewal (Sirianni \& Friedland 2001). Thus, civic ecology learning can be recognized when participants have a measurable impact on the communities and ecosystems, the so called social-ecological systems, in which they live (Kransy \& Tidball 2010).

The aim of this article is to bring forward the significant and multi-level role that civic ecology education plays in the case of natural disasters, in both the prevention process, before the occurrence of an extreme event and the recovery stage, after the outburst of the disaster. The role of the civic ecology education in the case of natural catastrophes is examined through the most extreme disaster that occurred in modern Greece: the forest fires in Peloponnese, in 2007. This study contributes to the ongoing research on the relative role and need of environmental education in empowering local societes with knowledge, elasticity, tolerance to the environmental hazard and resilient skills. Furthermore, this study connects the need for environmental education to the economic crisis reality, inderlining the fact that when the prevention and recovery measures organized by the state are a low priority, the urban environmental education is the only way to deal effectively with a natural hazard which may turn into a natural disaster. Lessons learned might set off changes of the education and training policies in both local and national level. 
The conceptual framework presented in this article intends to serve two main purposes: (1) suggest how environmental education might become linked to other activities and environmental educational practices that foster resilience and sustainability in social-ecological systems, enabling us to see the value of environmental education at the scale of a local socio-ecological system or even a small urban community; (2) propose the field of natural disasters through the paradigm of forest fires as a field in which civic ecology education could be effectively practiced due to the interaction of human and natural forces leading to its occurrence.

\section{Methodology}

A selection of people, who reside at Ilia, in the region of Peloponnese, was randomly done in order to choose the ones to whom the questionnaire was distributed. The specific area, which was so dramatically affected by the 2007 forest fires, has its local population still experiencing the consequences of this fire. A total of 150 individuals were interviewed during the summer of 2013. A descriptive statistical analysis (IBM SPSS Statistics v19) of the participants' responses was performed.

The questions included in the questionnaire are divided in three distinguished categories. The first group of questions examines the awareness of respondents about the phenomenon of forest fires in both environmental and social level and their sensibility in environmental issues as well. The second module of the questionnaire deals in depth with the awareness of respondents about the concept of Environmental Education, examining whether the local population of Ilia is familiar with the term Environmental Education and its role towards the prevention of forest fires. The third and final group of questions concerns the observation of the attitudes and the behavior of respondents towards the phenomenon of forest fires, defining their role as active citizens in the environmental decision-making process.

\section{Results}

The first group of questions concerned the awareness of respondents about the phenomenon of forest fires in both environmental and social level and their sensitivity towards the environmental issues. In the question that asked for the meaning of the term environmental damage, the majority of respondents representing the $62 \%$ stated that they did not know the answer while fully aware of the issue appeared to be only the $24 \%$ and partial knowledge of the issue had the remaining 14\%. Although the percentages of respondents who appeared to have knowledge of the concept of environmental destruction driven low, the results relating to the theme of knowledge of respondents about forest destruction and environmental sensitivity in general could be considered high. Specifically, in the question that asked what was the impact of forest fires in the environment, the majority of respondents representing the $84 \%$ clearly stated that the fire constitutes a parameter that directly affects the environment and even heavily, followed by a rate of $14 \%$ who believes that forest fires significantly affect the natural environment. Only the $2 \%$ of respondents answered that the phenomenon of forest fires affect less the environment. In addition, the majority of respondents not only felt that wildfires significantly affect the environment, but also the $96 \%$ of them linked the phenomenon of forest fires with the environmental destruction when asked if there is a potential connection between the wildfires and the environmental damage. Just a very small percentage of around $4 \%$ reported that they did not know the answer to this question (see Figure 1).

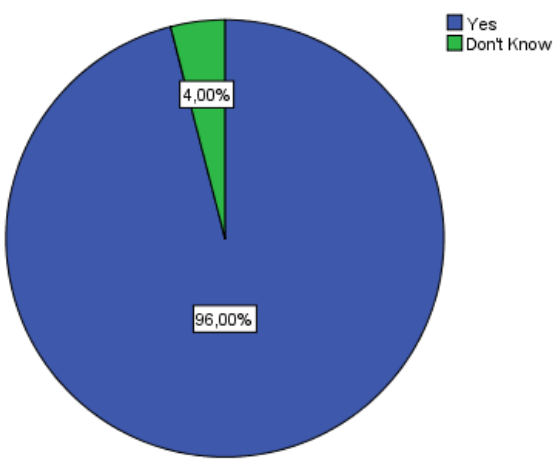

Figure 1. Forest fires as environmental disaster

The results obtained from the above questions fully justify the respondents' views on the extent of environmental destruction which was the next question of the interview. The majority of respondents which represents the $68 \%$ considered that the scale of environmental destruction nowadays is very large and follows a rate of $22 \%$ which feels great extent of the problem. The percentages that present the problem of environmental destruction moderate or less intense is limited and account for $8 \%$ and $2 \%$. The environmental sensitivity of respondents reflected in their responses regarding the magnitude of the problem of forest fires in the region of Ilia, and the causes and their impact on local communities. Within this context, in the question that concerned the extent of the phenomenon of forest fires in the 
wider area of Ilia, the $86 \%$ of respondents felt that the County suffers heavily from forest fires and follows a rate of $12 \%$ who believe that the region is very much affected by the problem. Finally, only a $2 \%$ felt that the area is not heavily affected from the phenomenon of forest fires.

Regarding the causes of forest fires, the majority of respondents corresponding to a $52 \%$ felt that the arson constitutes the most important factor that contributes to the spread of the phenomenon, followed by human negligence by a rate of $28 \%$. Also, the $70 \%$ of respondents stated that the natural causes of forest fires such as the lighting and the thunders are of minor importance, as it is less possible to cause a massive wildfire. What is more, it is found that the majority of respondents connected the issue of the forest fires with the local community, as when asked if the local community is affected by the occurrence of forest fires the most of them stated that this phenomenon directly affects the environment and the society as well. Specifically, the $98 \%$ of respondents answered affirmatively to the question concerning the association of the fire with the local community, while only the $2 \%$ stated that they did not know the answer. Also, in the question that asked about the most critical consequences of wildfires in the local society, the $50 \%$ of respondents pointed the loss of life as the most important aftermath of forest fires in the local community, followed by disturbance of the biodiversity at a rate of $34 \%$. According to the public opinion, the list of the consequences caused by forest fires to the local communities is completed with the reduction of the tourism and the damage to property at the rate of $8 \%$.

The awareness of the respondents towards the phenomenon of forest fires and their environmental sensitivity demonstrated by the results presented above is directly linked to the sources from which they choose to inform and educate themselves. Specifically, in the question that asked about their main sources of information, the $50 \%$ of respondents who constitute the majority of them said that the source of their information is the press (newspapers, television, radio), while the minority represented from the $2 \%$ reported that only information from local authorities (municipal authorities, Police, Fire Service). Also, it is important to mention that the $4 \%$ of respondents stated that their knowledge towards forest fires comes from their personal experience, as the questionnaire was distributed to residents directly affected by forest fires that hit Peloponnese during the summer of 2007. Finally, a considerable proportion of about $36 \%$ said that their information about wildfires comes from all the above sources of information, including both the press and the Internet and the information from local authorities as well.

Although the majority of respondents proved to be highly aware of all issues relating to forest fires and their connection to the environmental damage, it is not the case with the results of the second module of the research that measured the familiarity of respondents to the concept of Environmental Education and their awareness of the role it plays in the process of preventing and tackling forest fires. First of all, in the question that asked the exact meaning of the term Environmental Education, the vast majority of respondents representing the $60 \%$ admitted that they did not know the answer while only a rate of $26 \%$ proved to have full knowledge of the issue. Finally, the $14 \%$ of respondents answered that they had a partial knowledge of the term Environmental Education and its role. However, when asked if the Environmental Education could play a significant role in the prevention of wildfires, the $52 \%$ of respondents admitted that the Environmental Education can contribute decisively to prevent forest fires and follows a rate of $28 \%$ considering that the contribution of Environmental Education in the prevention of forest fires is very important. The percentages of respondents who considered the Environmental Education as an insufficient measure to prevent forest fires are generally low. Specifically, the $8 \%$ answered that the contribution of the Environmental Education in the prevention of wildfires is moderate, followed by rates of $10 \%$ and $2 \%$ who considered that the Environmental Education constitutes a limited or an inadequate measure to prevent forest fires.

Regardless the awareness of the public opinion towards the role of the Environmental Education programs, the results of the questionnaire pointed that the majority of respondents believe that the Environmental Education as a method of prevention of forest fires in Ilia is either non-existent or insufficient. Specifically, when asked if there are any Environmental Education programs organized in the area as a measure of prevention of wildfires, the $50 \%$ of respondents considered extremely limited the Environmental Education programs organized in the county and follows a rate of about $44 \%$ who describes those programs in the region as non-existent. Only the $2 \%$ of respondents believe that the organization of Environmental Education programs in the region is moderate, while the $4 \%$ consider the situation to be satisfactory. The same low rates of awareness that presented the respondents towards the role of Environmental Education are recorded in the case of volunteer programs. Specifically, in the question that asked about the exact meaning of the term voluntary program, the $60 \%$ of respondents admitted that they did not know the answer of this question, followed by the $22 \%$ which appears to have partial knowledge of the issue. Only the $14 \%$ of respondents answered that they were totally aware of the practices used by the volunteer programs.

In addition, in the question that asked about the public awareness for the conduction of Environmental Education programs in Ilia, the $68 \%$ of respondents reported that they had no information about the conduction of these kind of programs, while only the $32 \%$ stated that they were aware of the organization of relative programs in the wider area of Ilia (see Figure 2). 


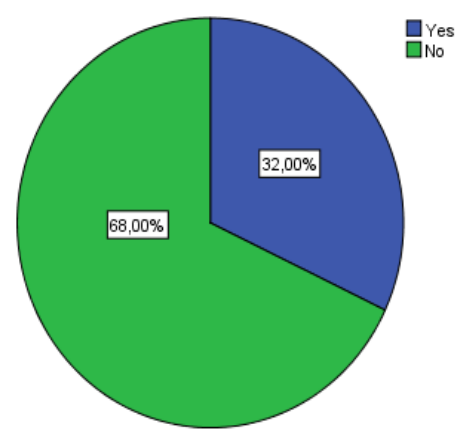

Figure 2. Awareness of environmental education programs

Also, in the question that asked about the opinion of the respondents about the role of the volunteer programs, the majority of them which corresponds to the $76 \%$ were in favor of the organization of training volunteer programs, as they appeared sure that they could lead to the efficient response to forest fires. The $20 \%$ of respondents presented more sceptic, stating that those programs could probably increase the efficiency of the forest fires planning, while the $4 \%$ appeared completely negative to this question (see Figure 3).

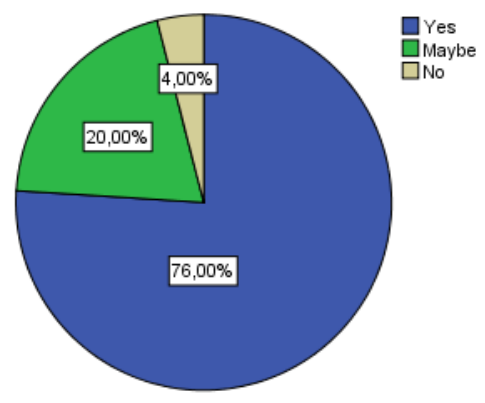

Figure 3. Volunteer program

The third and final module of the results obtained from the distribution of the questionnaire examines the attitudes and the behavior of respondents towards the phenomenon of forest fires, defining their role as active citizens in the decision-making process. First of all, in the question that asked if the respondents are members of any kind of environmental organizations all the answers received were negative. What is more, in the question that asked about the participation of the public in Environmental Education programs, an overwhelming majority of respondents representing the $98 \%$ admitted that they did not participate in suchprograms while only the $2 \%$ of them statedthat they had taken part in related programs (see Figure 4).

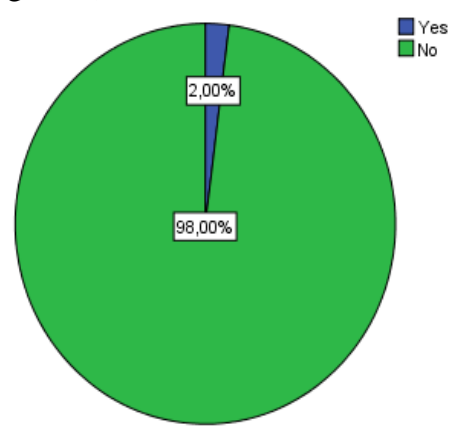

Figure 4. Participation

The percentages relating to participation in voluntary activities vary slightly, as shown higher both in relation to the participation of respondents in environmental organizations, and in relation to their participation in Environmental Education programs. Specifically, in the question that asked about the participation of the public in different kind of volunteer programs, the $16 \%$ of respondents reported that they have been participated in reforestation programs, the $10 \%$ stated that they had participated in food distribution programs, the $6 \%$ answered that they cleaned forest areas and the $6 \%$ stated that they have been participated in forest observation programs during summer season, when the danger of forest fires is extremely high. However important it is that the majority of these actions reported by the respondents that were organized by the community to which they belonged and in very few cases as a promoter of voluntary activity occurs public or private. 
Although the rates of active participation of the respondents in both environmental organizations and Environmental Education projects and volunteer programs appeared low, the results pointed that they consider the prevention of forest fires as a civic responsibility. Specifically, in the question that asked if the citizens could contribute to the isolation of the phenomenon of wildfires, the $98 \%$ support the idea that citizens could contribute to the reduction of forest fires while only the $2 \%$ of them said they did not know the answer in this question. Highlights are the results of the questionnaire related to respondents' views on the responsibility of prevention and treatment of forest fires. In the question that asked whose responsibility is the isolation of the phenomenon of wildfires, the vast majority of respondents representing the $82 \%$ expressed the view that the prevention and the treatment of forest fires constitute the collective responsibility of the state apparatus, local and municipal authorities and citizens as well.

In the same question, only the $16 \%$ of respondents expressed the view that the process of prevention and treatment of forest fires is the sole responsibility of the state apparatus, while $2 \%$ attaches liability to the citizens. Finally, in the question that asked if the state apparatus make a proper use of the dynamics of volunteer programs and of the Environmental Education projects in order to prevent forest fires, the $100 \%$ of respondents replied that neither the government nor the local authorities make the most of the possibilities of the volunteers and of the dynamics of Environmental Education programs in order to prevent more efficiently the forest fires and to lead the local communities to the recovery stage rapidly without causing more damages to the society.

\section{Conclusion}

Civic Ecology Education has a pivotal role in the prevention of natural disasters and the recovery process when a risk is experienced. The study of forest fires, within the broader context of sustainable development, mandates that we focus not only to the different climatic and environmental factors that cause such a natural disaster, but to the human activities that interact with such factors as well. Human actions and activities can reduce the risk associated with forest fires, both in the prevention and resilient aspects. The practice of Environmental Education determines the extent a forest fire can permanently affect the infrastructure and coherence of a local community and of the society in general.

Given that fact the global nature of natural disasters, forest fires one of them, and that they are associated with the environment and society, the creation of a global protection system which comes from the idea of Panarchy as it is proposed by Gunderson and Holling (2002) must be a priority. Based on the conceptual framework of Phanarchy, the impact of natural disasters in the environment and in the human socities must not be faced as an one-dimendion-problem in the different fields of ecology, ecomics or sociology. In contrast, when we talk about sustainable management, the discussion should include a combination of all parameters aiming to multi-faceted response to the different issues that arise and must be addressed within the framework defined sustainable development. Thus, the management of forest fires, when put in the context of sustainable development must be addressed through a comprehensive socio-ecological perspective that focuses both on the environment, economy and society, a relation that was addressed in this study.

Emphasis should be given on Civic Ecology Education strategies. Effective environmental awareness, can promote active citizen participation in the prevention, preparedness and mitigation of a forest fire. Through the assessment of the study's data, it was evident that respondents felt that central government played a weak role in the promotion of educational and resilient activities. This was reflected in their lack of awareness about available environmental education programs and resilience promotion activities. Voluntary organization and grouping was almost exclusively based on private initiatives and networking.

Therefore, multicenter and multilevel governance, citizen participation and collaboration, self- organization and networking, continuous learning and innovation are characteristics of societies that can claim that have invested in the promotion of environmental sustainability (Djalante, Holley and Thomalla 2011). The existence of multi-center and multi-faceted organizations contributes significantly to the strengthening of self -organization and the creation of networks and vice versa whiles the participation and cooperation can further accelerate the training process, learning and innovation. Within this context, the creation of a network which will be intergovernmental-having the ability to act in both national and local level-and cross-sectoral-meaning that the public, private and non-profit organizations will be able to act in different levels and cooperate with each other-is regarded as the cornerstone of a functioning adaptive governance. This kind of governance empowered with sound leadership and trust may trigger the desire of the public for participation and cooperation. Self-organization can be achieved through formal or informal manner by any structured public space while additionally can be accomplished through a variety of ways and networks (Pisano 2012). These networks in turn contribute to the processes of learning and innovation, creating the right conditions and cultivating the fertile ground on which to build a recovery aiming reinvention of social structures and the reopening of the social fabric in terms of risk and resilience elasticity limits of social tolerance.

In Greece, the Ilia forest fires of 2007, underline the absence of a recovery system based on well-established governmental processes. Additionally, the local authorities had a limited capacity to respond effectively. In contrast, the 
mobilization of the individuals and the cooperation of the residents of the affected area in conjuction with the active participation of the non-governmntal organizations and the volunteers from other areas were the only materials used in the building process of a resilient society during and after the traumatic forest fire experience in Ilia. Although the forest fires occurred in Ilia revealed the dynamics of the non-governmental organizations and the groups of volunteers, underlining the need for public participation and cooperation in such emergency cases, the impact caused in the local communities by that natural disaster proved that when individuals and volunteers operate without a well structure governmental and local authorities infrastructure, the outcome could be chaotic and the benefits debatable if not negative.

The present wide spread Greek economic crisis has placed the area recovery, from the forest fires of 2007, as a low priority. Respondents seem to have a crystal clear understanding that even if fate brought them against the same risk, the assistance that they would receive would be equally or even less adequate. The participants of this study know they need to be environmentally educated and learn to be resilient. They weren't aware that programs like this can be offered to them.

The human cost of the 2007 forest fires at Peloponnese is a scenario that should be an example to be avoided. In order though to assure safeguarding of human life, citizens must actively participate in the environmental decision making and if nothing else at least DEMAND for their right to environmental education and education for resilience.

\section{References}

Adger, W. N., Hughes, T. P., Folke, C., Carpenter, S. R., Rockström, J. (2005). Social-ecological resilience to coastal disasters. Science, 309, 1036-1039.

Abbott, P. L. (2013). Natural disasters. McGraw-Hill.

Ardoin, N. (2006). Toward an interdisciplinary understanding of place: Lessons for environmental education. Canadian Journal of Environmental Education, 11, 14.

Barnett, M., Lord, C., Strauss, E., Rasca, C., Langford, H., Chavez, D., \& Deni, L. (2006). Using the urbanenvironment to engage youths in urban ecology field studies. Journal of Environmental Education, 37, 3-11.

Bassi, S., \& Kettunen, M. (2008). Forest fires: Causes and contributing factors in Europe. European Parliament, Brussels. Retrieved from http://www.ieep.eu/assets/392/forest_fires_report.pdf. Accessed date: $5^{\text {th }}$ October 2013

Carpenter, S., Arrow Kenneth, R., Barrett, J., Biggs, S., Reinette, B., William, A., ... Aart. (2012). General Resilience to Cope with Extreme Events. Sustainability, 4, 3248-3259.

Coch, N. K. (1995). Geohazards. Natural and human, New Jersey: Prentice Hall Inc.

Djalante, R., Holley, C., \& Thomalla, F. Adaptive Governance and Managing Resilience to Natural Hazards. Int. J. Disaster Risk Sci., 2, 1-14.

Folke, C. (2006). Resilience: The emergence of a perspective for social-ecological systems analysis. Global Environmental Change, 16, 253-267.

Folke, C., S. Carpenter, T. E., Gunderson, L., Holling, C. S., Walker, Bengtsson, B., J., ... Svedin, U. (2002). Resilience and sustainable development: building adaptive capacity in a world of transformations, Johannesburg, South Africa.

Frank, J., Zamm, M., Benenson, G., Fialkowski, C., \& Hollweg, K. (1994). Urban Environmental Education. The Environmental Education Toolbox, University of MI, Ann Arbor, MI, USA.

Hoffman, M. S., \& Anthony, O. S. (ed.). (2002).Catastrophe and Culture: The anthropology of disaster. Santa Fe, New Mexico: School of American Research Press.

Grimm, N. B., Grove, J. M., Pickett, S. T. A., \& Redman, C. L. (2000). Integrated Approaches to Long- Term Studies of Urban Ecological Systems BioScience, 50, 571-584.

Gunderson, L. H., \& Holling, C. S. (Eds). (2002). Panarchy: Understanding Transformations in Human and Natural Systems. Washington D.C.: Island Press.

Kahn, M. (2005). The death toll from natural disasters: the role of income, geography and institutions. Review of Economics and Statistics, 87, 271-284.

Keith, S. (2001). Environmental Hazards: Assessing risk and reducing disaster. Third edition. London and New York: Routledge.

Koutsias, N., Arianoutsou, M., Kallimanis, A. S., Mallinis, G., Halley, J. M., Dimopoulos, P. (2012). Where did the fires burn in Peloponnisos, Greece in the summer of 2007? Evidence for a synergy of fuel and weather. Agricultural and Forest Meteorology, 156, 41-53. 
Krasny, M. E., \& Roth ,W. M. (2010). Environmental education for social-ecological system resilience: a perspective from activity theory. Environmental Education Research, 6, 545-558.

Krasny, M. E., Lundholm, C., \& Plummer, R. (2010). Resilience, Learning and Environmental Education. Environmental Education Research, 6, 665-672.

Krasny, M. E., Kalbacker, L., Stedman, R., \& Kudryavtsev, A. (2010). Development of an instrument to measure social capital with youth, North American Association of Environmental Education Research Symposium, Buffalo, NY, USA.

Krasny, M. E., \& Doyle, R. (2002). Participatory approaches to extension in a multi-generational, urban community gardening program. Journal of Extension, 40.

Krasny, M. E., \& Bonney, R. (2005). Environmental education through citizen science and participatory action research: the Cornell Laboratory of Ornithology and Garden Mosaics examples, in: M. Mappin and E. A. Johnson (Eds.), Environmental Education or Advocacy: Perspectives of Ecology and Education in Environmental Education, Cambridge University Press, Cambridge UK.

Krasny, M. E., \& Tidball, K. G. (2009). Community gardens as contexts for science, stewardship, and civic action learning. Cities and the Environment, 2, 8.

-----. (2010). Civic Ecology: Linking social and ecological approaches in extension. Journal of Extension, 48(1).

Krasny, M. E., Tidball, K. G., \& Sriskandarah, N. (2009). Education and resilience: Social and situated learning among university and secondary students. Ecology and Society, 14(2), 38.

Kudryavtsev, A., Stedman, R., \& Krasny, M. E. In Press. Sense of Place in Environmental Education. Environmental Education Research.

Kudryavtsev, A., Krasny, M. E., Elmqvist, T., Bain, M., \& Henning, D. (2011). In Press. Facilitating social learning in urban environmental education, Resilience 2011: Second International Science and Policy Conference, Tempe, AZ, USA.

Lyons, M., Schilderman, T., \& Sanderson, D. (2011). Harnessing time: Reflections on constraints to development. Environmental Hazards, 10, 213-217.

MacKinnon, D., \& Derickson, K. D. (2012). From resilience to resourcefulness: A critique of resilience policy and activism. Progress in Human Geography, 1-18.

Mutter, J. (2010). Disasters widen the rich-poor gap. Nature, 466, 1042.

Rogerson, A. (2005). The International Aid System 2005-1010, Forces For and Against Change. www.odi.org.uk/publications/web_papers/aid_system_rogerson.pdf.

Stapp, W. B. (2001). The concept of environmental education, in: H. R. Hungerford, et al. (Eds.), Essential Readings in Environmental Education, Stipes Publishing, LLC, Champaign, IL, USA. pp. 33-36.

Skanavis, C. (2005). Environment and Society. Right to Choose. Athens: Kaleidoscope.

Tompkins, E. L., Hurlston, L. A. (2012). "Public-Private Partnership in the Provision of Environmental Governance: A Case of Disaster Management" in Adapting Institutions: Governance, Complexity and Social-Ecological Resilience. Boyd, E., Folk, C. (Eds.). Cambridge: Cambridge University Press.

Tidball, K. G., \& Krasny, M. E. (2007). From risk to resilience: What role for community greening and civic ecology in cities? , in: A. E. J. Wals (Ed.), Social Learning Towards a more Sustainable World, Wagengingen Academic Press, Wagengingen, The Netherlands.

Veselinovska, S. S., Gokik, M., \& Veselinovski, M. (2011). Awakening of the global awareness. Procedia - Social and Behavioral Sciences, 15, 1214-1219.

Walker, B., \& Salt, D. (2006). Resilience Thinking. Washington DC: Island Press.

Waugh, W. L. (2000). Living with hazards, Dealing with disasters: An introduction to emergency management. New York and London: M.E. Sharp.

Wimberley, E. T. (2009). Nested Ecology: the Place of Humans in the Ecological Hierarchy, The Johns Hopkins University Press, Baltimore MD, USA.

\section{(c)) EY}

This work is licensed under a Creative Commons Attribution 3.0 License. 